\title{
Investigation of the Effects of Reward Granting Program on Purchase Purpose, Type and Timing of Reward
}

\author{
Ayoub Pourkhosravi \\ Department of Business Management, Qazvin Branch, Islamic Azad University, Qazvin, Iran \\ Kambiz Heidarzadeh Hanzaee \\ Department of Business Management, College of Management and Economics, \\ Tehran Science and Research Branch, Islamic Azad University, Tehran, Iran \\ Corresponding Author: Email: kambizheidarzadeh@yahoo.com, Tel: +98-21-44865179
}

Doi:10.5901/mjss.2014.v5n23p2760

\begin{abstract}
Some attempts have been made for establishing balance between supply and demand within the framework of demand management, service-providing processes and service employees for firms with limited service capacity. Apart from the importance of the role of customers in serving process, many attempts have been made to manage customers' roles. In the present research, the author investigates the impact of a reward granting program (as a customer solution and empirical test of effectiveness) on purchase purpose, type and timing of reward. Furthermore, it tests customer's voluntary behavior which is to firm's benefit. In the present research, 237 students were surveyed. Data were analyzed by means of exploratory and confirmatory factor analyses and structural equations modeling. Results showed that customers' understanding of restaurant's right to gain profit has a direct impact on customers' attempts for shortening eating time (after receiving a reward plan). Further, fair evaluation of reward granting plan and customer's understanding of restaurant's right to gain profit have direct impacts on accepting rewarding plan.
\end{abstract}

Keywords: service capacity management, customer's reward, customer's citizenship behavior, common production behavior.

\section{Introduction}

For decades, a company's value was evaluated by means of its properties, tangible assets, factories and equipment. Now, however, real value of a company is in minds of potential purchasers (Heidarzadeh et al, 2011). Different industries are growing rapidly in the present era. Service industry sector plays an important role in competition world especially in fields like technology, tourism, hoteling and restaurants. CS is a sort of an aggregate assessment of experiences gathered through time and interactions with companies by customers (Heidarzadeh, 2014). Therefore, use of the results of scientific studies is important in improvement of service providing processes in order to maximize firms' profits. The present era is accompanied with unpredictable changes and companies are confronted with factors like unclear boundaries of markets, segmentation of markets, short products lifecycles, rapid change in customers' purchase models and knowledgeable customers (Rahnama et al, 2012). The present research aims to investigate the impact of reward plan on purchase objective, type and timing of reward-granting plan. In addition to defining concepts like firms' service capacity, reward granting program, different types of rewards, reward timing and customer's citizenship behavior, the author investigates the impact of reward granting plan and customer's behavior stimulation on firms' with limited service capacity. The most important challenge head of restaurants is their limited capacity in providing services for customers. Therefore, the main question is as follows: what is the impact of reward granting plan on purchase purpose, type and timing of reward granting?

\section{Theoretical Literature}

Service Capacity Management: since 1970s, firms with limited serving capacity tried their best to maximize their revenues via matching demand with supply (Cross, 1977). The term "revenue management" was devised to refer to these attempts and was defined as "selling real inventory to real customers at real prices in real time for maximizing profits" (Smith et al, 1992). Revenue management applies to companies with commercial features like: relatively constant capacity, time- 
perishable inventory, time-variable demand and high fixed costs (Kimes, 1999). These viewpoints try to minimize serving time and eliminating unnecessary delays (Choi and Kim, 2013). Customer Impact On Service Capacity: for the case of service companies, customers' role in serving processes is effective on organizational performance and productivity. Customer's participation can increase productivity, efficiency and can improve service providing. Moreover, this participation has a positive impact on understanding services quality and customers' satisfaction. In fact, customers' participation can improve understanding of the quality of services provided for customers (Hsieh et I, 2004). Service customers are resources for contribution to services value and quality (Bitner et al, 1997). Service firms' customers play important roles in specifying the service providing time and capacity of serving. Therefore, service companies' managers tend to reduce those customers' behaviors which reduce serving time. This is true especially when supply exceeds demand (Hsieh et al, 2004). Customers' real role behaviors are necessary for successful production and offer of services (Groth, 2005). Extraordinary roles behaviors (customer citizenship behaviors) are voluntary behaviors of customers and include collaboration, profitability and kindness (Choi and Kim, 2013). Customers' collaboration is a key to absorb and keep customers and a key to other qualitative perceptions of customers and satisfaction with serving process (Kelly et al, 1992). Customer collaboration behaviors are attempts made by customers for understanding serving process, behaving politely and sociably, observation of rules, policies and acceptance of necessary guidance by service providers (Choi and Kim, 2013). Fair evaluation of reward program: customers' fair evaluation of reward plan is effective in program effectiveness (Chatman, 1991; Greenberg, 1987). Customers' fair understanding of reward program means: customer's satisfaction with what he or she receives in comparison with what he or she expected in return for attempts and loyalties they show in transaction" (Homans, 1958). When a reward program is identified as unfair, customers lose their motivations and become dissuaded to establish relationship with reward providers (Ganesan, 1994). Perceptions of fair evaluation affect dimensions of organizational citizenship behavior. Therefore, when a reward plan is evaluated as fair, that reward plan can stimulate customer's demand for establishment of relationship with providers and attracts positive attitudes. Further, stimulated favorable attitudes can contribute to success of a reward plan (Moorman, 1991). Customer's reward: reward can result in customers' stimulation to accept customer citizenship behavior (Puffer, 1987). Rewards offering improves fair perception of customers and stimulates rewarded behaviors (Moorman, 1991). Service customers usually play role when they are rewarded for any behavior (Yi et al, 2004). When customers are rewarded for their collaborative behaviors, they feel they are cared about. Moreover, some advantages of implementation of rewarding programs and loyalty plans include:

First: the cost of provision of service for loyal customers is low.

The attitude toward performing the behavior is an individual's positive or negative belief about the performing of the specific behavior (Sadeghi, Heidarzadeh, 2010).

Second: loyal customers have low sensitivity to prices changes.

Third: loyal customers spend more time with the firm (Dowling \& Uncles, 1997).

Therefore, individuals try to return benefits they receive from others.

Selection of customers, reward characteristics and customers' characteristics: effectiveness of rewarding plan can depend on plan features. When a reward plan is proposed, customers' expected behaviors depend on their selections (Choi and Kim, 2013). Individuals can make decisions based on their feelings and without the smallest attention to knowledge about a particular product; they decide to purchase the product (Abdolvand et al, 2011). Customers who select reward plan show rewarded behaviors.

\section{Reward Features and Customer Characteristics}

Customers like rewards which are directly related to sold products and services like: price discounts (in comparison with discount coupons for other products or services) and rewards which can be immediately returned (in comparison with postponed rewards) (Keh\& Lee, 2006). One of the other features of reward is immediate granting (Dowling \& Uncles, 1997). Needs and preferences of customers result in diversity of purchase $s$ which can be classified within the framework of two types of purchase: (1) utilitarian purposes and (2) hedonic purposes (Babin \& Griffin, 1994). Utilitarian customers are those who pay a lot of attention to efficiency and appropriateness of purchase. However, hedonic customers are those who pal a lot of attention to hedonistic aspects and fun aspects of purchase (Choi and Kim, 2013). Therefore, when purchase has a hedonistic nature, a reward which supports hedonistic purposes will be more effective.

Considering the above literature, the following hypotheses are proposed for investigation:

H1: customers' perception of restaurants right in acquiring profit and purchase purpose has a direct impact on customer's attempt for shortening eating time (after receiving a reward).

$\mathrm{H}$ 2: fair evaluation of reward program, purchase purpose and customer's perception of restaurant's right for gaining 
profit has a direct impact on rewarding plan acceptance.

H3: customers' attempt for shortening eating time after receiving a rewarding plan is more than when a reward plan is not received.

H4: customers' attempts for shortening eating time after receiving a reward plan is more in customers who tend to accept rewarding plan than customers who do not tend to accept reward plans.

$\mathrm{H} 5$ : there is a difference between customers' attempt for shortening eating time without receiving a rewarding plan and after receiving a rewarding plan.

H6: there is difference between customers' attempts for shortening eating time without receiving a rewarding plan and after receiving a plan for purchase purpose.

$\mathrm{H} 7$ : there is difference between customers' attempt for shortening eating time without receiving a rewarding plan and after receiving a plan for reward timing.

\section{Methodology}

The present research investigates customers' behavior based upon an empirical scenario-based design for testing research hypotheses. In the present research, confirmatory factor analysis was used for testing the hypotheses. Furthermore, structural equations modeling method based on least partial squares was used for testing the hypotheses. SPSS and AMOS software were used for analyzing research data (Qasemi, 2011).

In the present research, data were collected by a standard questionnaire. Since the present research involves factor analysis, combination of the three factors (purchase purpose, reward type and reward granting timing) gave 8 different scenarios as: 2(purchase purpose: hedonic and utilitarian)*2(reward timing: immediate or delayed)*2(reward type: direct or indirect). These scenarios were designed and presented as follows:

First part: in this section, participants were asked to assume a restaurant which has been opened about three months ago and their friends told them that all its pudding, starters and meals are delicious and it is very famous. Further, restaurant's management has tried to design a good decoration and play soothing music and employ young waiters to give energy to the restaurant. When you enter the restaurant for lunch, it is very crowded and there is hardly any unoccupied place to sit. You can find many people who came there to eat fast and frugal foods.

Second part: in this section, because the restaurant is two crowded, restaurant's management proposes to customers that if they eat and leave the restaurant within 30 minutes, they will be rewarded because of their collaboration and consideration.

We conducted the first pretest with 8 scenarios and 24 students-one scenario for three students- and the second pretest with 16 students-one scenario for two students- so that the results of validity and reliability of the questionnaires and scenarios were measured and summarized in table 1-3. Results show that all alpha coefficients are above 0.6. Therefore, internal consistency of the questionnaire is verified. Further, convergent validity is verified because average variance extracted (AVE) of all three constructs were greater than 0.50 . Respondents were 240 students of humanities and social sciences and educational sciences and psychology faculties in Tabriz University. 237 questionnaires were complete and used for analysis.

\section{Results of hypotheses tests}

SPSS software was used for testing the hypotheses and building data and their frequencies. Further, AMOS software was used for implementation of structural equations modeling method.

Table 1: coefficient of impact of restaurant's right to gain profit and purchase purpose on reducing eating time

\begin{tabular}{|c|c|c|c|c|c|}
\hline \multirow{2}{*}{ Significance level } & \multirow{2}{*}{ T statistic } & Standard coefficient & Non-standard coefficient & \multirow{2}{*}{ Other variables } \\
\cline { 3 - 5 } & & Beta coefficient & Standard error & B coefficient & \\
\hline 0.000 & 5.185 & & 0.263 & 1.362 & Constant coefficient \\
\hline 0.000 & 7.271 & 0.429 & 0.082 & 0.595 & Right for gaining profit \\
\hline 0.961 & 0.049 & 0.003 & 0.115 & 0.006 & Purchase purpose \\
\hline \multicolumn{4}{|r|}{$\mathrm{F}=26.438, \mathrm{p}=.000, \mathrm{R}$ Square $=.184, \mathrm{R}=.429$, Std. Error of the Estimate $=0.88646$} & \\
\hline
\end{tabular}

Table 1 shows that impact coefficient for the first hypothesis is equal to 0.429 and the calculated $t$ statistic is equal to 7.271 and significance level is smaller than $0.01(t=7.271, p<0.01)$. This shows that there is a direct and significant 
relationship between customers' understanding of restaurant's right to gain profit and customers' attempts for shortening eating time by receiving a reward plan. However, purchase purpose does not have any influence on customers' attempt for shortening eating time (after receiving a rewarding plan).

Table 2: test of impact of restaurant right to gain profit on reduction of eating time

\begin{tabular}{|c|c|c|c|c|c|}
\hline \multirow{2}{*}{$\begin{array}{l}\text { Significance level } \\
\text { B coefficient }\end{array}$} & \multirow{2}{*}{ T statistic } & \multirow{2}{*}{$\begin{array}{l}\text { Standard coefficient } \\
\text { Beta coefficient }\end{array}$} & \multicolumn{2}{|c|}{ Non-standard coefficient } & \multirow{2}{*}{ Other variables } \\
\hline & & & Standard error & B coefficient & \\
\hline 0.329 & -0.978 & & 0.280 & -0.274 & Constant \\
\hline 0.000 & 3.816 & 0.242 & 0.087 & 0.332 & Fair evaluation of reward \\
\hline 0.000 & 5.496 & 0.348 & 0.085 & 0.467 & Right for gaining profit \\
\hline 0.604 & 0.520 & 0.029 & 0.107 & 0.056 & Purchase purpose \\
\hline \multicolumn{5}{|c|}{$F=26.836, p=.000, R$ Square $=.257, R=.507$, Std. Error of the Estimate $=0.82087$} & \\
\hline
\end{tabular}

Results of regression analysis for the second hypothesis in table 2 show that impact coefficient is equal to 0.242 and the calculated $t$ statistic is equal to 3.816 and significance level is smaller than $0.01(t=3.816, p<0.01)$. This shows that fair evaluation of reward granting program has a direct and significant impact on the dependent variable (tendency to accept rewarding program in statistical population). Further, impact coefficient between customers' understanding of restaurant's right for gaining profit and tendency to accept rewarding program is equal to 0.348 and the calculated t statistic is equal to 5.496 and significance level is smaller than 0.01 ( $t=5.496, p<0.01)$. Therefore, customers' understanding of restaurant's right for gaining profit has a direct and significant impact on tendency to accept a rewarding program. However, purchase purpose does not have any influence on tendency to accept reward plan.

Table 3: test of comparison of mean value of reduction in eating time in case of presence/absence of reward

\begin{tabular}{|c|c|c|c|c|c|c|}
\hline $\begin{array}{c}\text { Significance } \\
\text { level }\end{array}$ & df & $\begin{array}{c}\mathrm{T} \\
\text { statistic }\end{array}$ & $\begin{array}{c}\text { Mean } \\
\text { difference }\end{array}$ & \multicolumn{2}{|c|}{ Empirical mean in two conditions: } & Subtraction of two variables \\
\hline 0.000 & 236 & 4.433 & 0.24191 & 3.1800 & Without reward & \\
\hline
\end{tabular}

Results of the third hypothesis test in table 3 show that the calculated statistic is equal to 4.433 which is greater than the critical value 1.96 and significance level is smaller than $0.01(T=4.433, p<0.01)$. Therefore, customers try to shorten their eating time in case of presence of a reward program and the corresponding hypothesis is supported.

Table 4: comparison of mean values of reduction in eating time with reward in the two groups with low/high tendencies

\begin{tabular}{|c|c|c|c|c|c|c|c|c|c|c|}
\hline \multicolumn{4}{|c|}{ Comparison of means ${ }^{2}$} & \multicolumn{2}{|c|}{ Comparison of variances ${ }^{1}$} & \multicolumn{2}{|c|}{ Empirical mean } & \multicolumn{2}{|c|}{ number } & \multirow[b]{2}{*}{ Variable and index } \\
\hline $\begin{array}{c}\text { Mean } \\
\text { difference }\end{array}$ & $\begin{array}{l}\text { Error } \\
\text { level }\end{array}$ & $d f$ & $\begin{array}{c}\mathrm{T} \\
\text { statistic }\end{array}$ & $\begin{array}{l}\text { Error } \\
\text { level }\end{array}$ & F statistic & $\begin{array}{l}\text { High } \\
\text { tendency }\end{array}$ & $\begin{array}{c}\text { Low } \\
\text { tendency }\end{array}$ & $\begin{array}{c}\text { High } \\
\text { tendency }\end{array}$ & $\begin{array}{c}\text { Low } \\
\text { tendency }\end{array}$ & \\
\hline-0.085049 & 0.000 & 235 & -7.058 & 0.413 & 0.674 & 3.7255 & 2.8750 & 85 & 152 & $\begin{array}{c}\text { Customer's attempt for reducing } \\
\text { eating time after receiving } \\
\text { reward }\end{array}$ \\
\hline
\end{tabular}

Results of the fourth hypothesis test in table 4 show that the calculated statistic is equal to 7.058 and is greater than the critical value 1.96 and the significance level is smaller than $0.01(T=4.433, p<0.01)$. The results show that customers with high tendency to accept rewarding program in return for shortening eating time try more than customers with low tendency. Therefore, the corresponding hypothesis is supported. 
Table 5: principle and interactive impacts of reward type variable on subtraction of reduction of purchase time in two states

\begin{tabular}{|c|c|c|c|c|}
\hline Sig. & F statistic & Kai-Square mean & Independent variable & row \\
\hline 0.073 & 3.252 & 2.265 & Reward type(RTY) & 2 \\
\hline 0.184 & 1.777 & 1.238 & Purchase purpose $\times$ reward type(POP $\times$ RTY $)$ & 4 \\
\hline 0.607 & 0.265 & 0.185 & Reward type $\times$ reward timing $(\mathrm{RTY} \times \mathrm{RTI})$ & 6 \\
\hline 0.736 & 0.114 & 0.080 & Purchase purpose $\times$ reward type $\times$ reward timing(POP $\times$ RTY $\times$ RTI) & 7 \\
\hline
\end{tabular}

In order to test the hypotheses 5 to 7 , mutual impacts of variables: purchase purpose, reward type and reward granting timing were analyzed in a model of factorial variance analysis. According to the results of univariate covariance test and table 5, the calculated statistic for main impact of reward type is equal to 3.252 and significance level is greater than 0.05 $(F=3.252, p>0.05)$ and the fifth hypothesis is not supported. Therefore, there is no difference between customers' attempt for shortening eating time without receiving a reward plan and after receiving a reward plan in reward type.

Table 6: main and mutual impacts of purchase purpose on subtraction of reduction in purchase time in two conditions

\begin{tabular}{|c|c|c|c|c|}
\hline Sig. & F statistic & Kai-squared mean & Independent variable & row \\
\hline 0.980 & 0.001 & 0.000 & Purchase purpose $(\mathrm{POP})$ & 1 \\
\hline 0.184 & 1.777 & 1.238 & Purchase purpose $\times$ reward type $(\mathrm{POP} \times \mathrm{RTY})$ & 4 \\
\hline 0.046 & 4.023 & 2.801 & Purchase purpose $\times$ reward timing(POP $\times$ RTI) & 5 \\
\hline 0.736 & 0.114 & 0.080 & Purchase purpose $\times$ reward type $\times$ reward timing(POP $\times$ RTY $\times$ RTI) & 7 \\
\hline
\end{tabular}

Results of the $6^{\text {th }}$ hypothesis test in table 6 show that the calculated statistic for main principle of purchase purpose is equal to 0.001 and significance level is greater than $0.05(F=0.001, p>0.05)$, the calculated statistic for mutual impact between purchase purpose and reward type is equal to 1.777 and significance level is greater than 0.05 ( $F=1.777$, $p>0.05$ ) and the calculated statistic for mutual impact between purchase purpose and reward granting timing is equal to 4.023 and the corresponding significance level is smaller than $0.05(F=4.023, p<0.05)$. Therefore, it can be said that there is no difference between customer's attempt for shortening eating time without receiving a rewarding plan and after receiving a rewarding plan in the field of purchase purpose. However, there is a difference between customer's attempt for shortening eating time without receiving a rewarding plan and after receiving a rewarding plan in the field of purchase purpose and interaction with timing of reward granting. However, the principle impact is not significant in general.

Table 7: principle and mutual impacts of reward timing on subtraction of reduction in timing in two conditions

\begin{tabular}{|c|c|c|c|c|}
\hline Sig. & F statistic & Kai-squared mean & Independent variable & row \\
\hline 0.435 & 0.611 & 0.426 & Reward timing(RTI)( & 3 \\
\hline 0.046 & 4.023 & 2.801 & Purchase purpose * reward timing(POP * RTI) & 5 \\
\hline 0.607 & 0.265 & 0.185 & Reward type * reward timing (RTY * RTI) & 6 \\
\hline 0.736 & 0.114 & 0.080 & Purchase purpose * reward type * reward timing $\left(\mathrm{POP} * \mathrm{RTY}^{*} \mathrm{RTI}\right)$ & 7 \\
\hline
\end{tabular}

Results of univariate covariance test in table 7 show that the calculated statistic for principle impact of reward timing is equal to 0.611 and significance level is greater than $0.05(\mathrm{~F}=0.611, \mathrm{P}>0.05)$, the calculated statistic for mutual impact of reward timing on reward type is equal to 1.777 and significance level is greater than 0.05 ( $F=1.777, p>0.05)$, and the calculated statistic for mutual impact of purchase target on reward timing is equal to 4.023 and its significance level is smaller than $0.05(\mathrm{~F}=4.023, \mathrm{p}<0.05)$ and the calculated statistic for reward timing impact on purchase target and reward type is equal to 0.114 and its significance level is greater than $0.05(\mathrm{~F}=0.114, p<0.05)$. Therefore, it can be said that there is no difference between customer's attempt for shortening eating time without receiving a rewarding program and after receiving a reward program in the field of rewarding timing. However, there is a difference between customer's attempt for shortening eating time without receiving a rewarding plan and after receiving a rewarding plan in the field of reward granting timing and its impact on purchase purpose. However, the principle impact is not significant in general. 


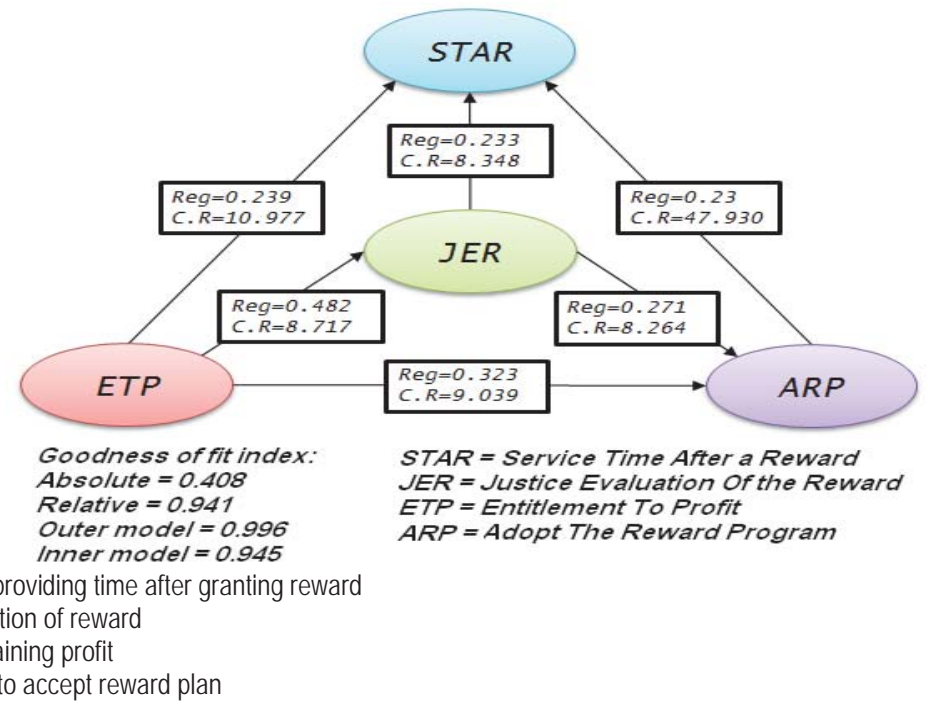

Figure 1: impact coefficients of effective constructs on effect-receiving constructs in the variance-oriented structural part of the model

Table 8: table of the role of variables, used test and results of research hypotheses

\begin{tabular}{|c|c|c|c|c|}
\hline Test result & test & Dependent variable & $\begin{array}{l}\text { Independent } \\
\text { variable }\end{array}$ & hypothesis \\
\hline $\begin{array}{c}\text { Direct and significant } \\
\text { impact }\end{array}$ & Regression analysis & Reduction in purchase time & $\begin{array}{l}\text { Right for gaining } \\
\text { profit }\end{array}$ & \multirow{2}{*}{$\begin{array}{c}\text { First } \\
\text { hypothesis }\end{array}$} \\
\hline Insignificant impact. & Regression analysis & Reduction in purchase time & Purchase purpose & \\
\hline $\begin{array}{l}\text { Direct and significant } \\
\text { impact }\end{array}$ & Regression analysis & On tendency to accept reward & Fairness of reward & \multirow{3}{*}{$\begin{array}{c}\text { Second } \\
\text { hypothesis }\end{array}$} \\
\hline $\begin{array}{c}\text { Direct and significant } \\
\text { impact }\end{array}$ & Regression analysis & On tendency to accept reward & Right for gain profit & \\
\hline Insignificant impact. & Regression analysis & On tendency to accept reward & Purchase purpose & \\
\hline Significant impact & Paired mean comparison & Reduction in purchase time & Rewarding program & $\begin{array}{c}\text { Third } \\
\text { hypothesis }\end{array}$ \\
\hline Significant impact & $\begin{array}{l}\text { Comparison of means of two } \\
\text { independent variables }\end{array}$ & $\begin{array}{c}\text { Reduction in eating time in return for } \\
\text { reward }\end{array}$ & $\begin{array}{c}\text { Tendency to accept } \\
\text { reward }\end{array}$ & $\begin{array}{c}\text { Fourth } \\
\text { hypothesis }\end{array}$ \\
\hline $\begin{array}{c}\text { Principe impact is not } \\
\text { significant. }\end{array}$ & $\begin{array}{l}\text { Principle impact of variance } \\
\text { analysis, (factorial) (factor) }\end{array}$ & $\begin{array}{l}\text { Difference between reduction in purchase } \\
\text { time in reward and no-reward cases }\end{array}$ & Reward type & $\begin{array}{c}\text { Fifth } \\
\text { hypothesis }\end{array}$ \\
\hline $\begin{array}{c}\text { Principe impact is not } \\
\text { significant. }\end{array}$ & $\begin{array}{l}\text { Principle impact of variance } \\
\text { analysis, factorial (factor) }\end{array}$ & $\begin{array}{l}\text { Difference in purchase time reduction } \\
\text { between reward and no-reward cases }\end{array}$ & Purchase purpose & $\begin{array}{c}\text { Sixth } \\
\text { hypothesis }\end{array}$ \\
\hline $\begin{array}{l}\text { Principe impact is not } \\
\text { significant. }\end{array}$ & $\begin{array}{l}\text { Principle impact of variance } \\
\text { analysis, factorial (factor) }\end{array}$ & $\begin{array}{l}\text { Difference in purchase time reduction in } \\
\text { reward and no-reward cases }\end{array}$ & Reward timing & $\begin{array}{c}\text { Seventh } \\
\text { hypothesis }\end{array}$ \\
\hline
\end{tabular}

Considering the results of statistical analyses, results supported four hypotheses but three hypotheses were rejected. Results of research hypotheses tests have been summarized in table 8.

\section{Conclusion}

The present research investigated "the impact of reward granting program on purchase purpose, type and timing of reward granting". Results showed that customers' understanding of restaurant's right for gaining profit has a direct influence on customer's attempt for shortening eating time (after receiving a rewarding plan) but the impact of purchase purpose on customer's attempt for shortening eating time (after receiving a rewarding program) was not significant (first hypothesis). Choi and Kim (2013) also showed that customers' understanding impact was significant. Therefore, 
customers' understanding of stimulants of service firm like reward granting program and response to it is positive. Therefore, recognition of demographic features of customers, reward type and its granting timing can stimulate customers and create a satisfaction feeling and make use of customers' perception to minimize eating time and profit gaining. Considering the direct impact of fair evaluation of reward granting plan and customers' perception of restaurant's right for gaining profit on tendency to accept rewarding program and lack of influence of purchase purpose on tendency to accept rewarding program (second hypothesis) (verified by Choi and Kim in 2013), operationalization of the slogan: "customer is right" along with high quality of services causes customers to have a fair evaluation of reward-granting plan and company's right for gaining profit. Therefore, technical training of employees to enable them to serve customers well and show respect to customers, supportive coverage of employees within the framework of increasing wages and salaries and perks in order to serve customers well and increase profitability, exactness in reward preparation costs and reward type with respect to environment and society will be important duties of managers. Results also showed those customers' attempts for reducing eating time after receiving a rewarding program was more than that of no-reward case (verification of the third hypothesis) and this conforms to the result of Choi and Kim (2013). In addition to the impact of reward granting programs on reduction in eating time in rush hours, granting of different rewards can attract customers and satisfy them and promote via word-of-mouth marketing.

Considering the fact that customers' attempts for reducing eating time after receiving a reward was more in customers with high tendency to accept rewarding program than customers who did not have any tendency to accept reward (fourth hypothesis), a service firm must be careful in crowded hours to be able to identify utilitarian customers and grant reward to them to provide enough space and environment for customers with hedonic purposes. Since there was no difference between customers' attempts for shortening eating time without receiving a reward plan and after receiving a reward plan in the field of reward type (rejection of the fifth hypothesis), the restaurant must implement a segmentation program in terms of purchase purpose variable for customers with utilitarian purposes (for instance travelers or hungry individuals) and implement indirect and non-immediate reward programs. Although there is no difference between customers' attempt for shortening eating time without rewarding and after receiving a reward program in terms of purchase purpose and timing of reward granting program (rejection of the sixth and seventh hypotheses), recognition of customers' purchase purpose in effectiveness of the type of implementation of reward timing is important because there is a difference between customers' attempt for reducing eating time without receiving a rewarding program and after receiving a rewarding program in terms of purchase purpose and its interaction with reward granting program timing. Therefore, the restaurant must try to identify customers' purchase purposes.

\section{References}

Abdolvand, Mohammad Ali; Heidarzadeh Hanzaee, Kambiz; Rahnama, Afshin; Khoshpanjeh, Mahsa., (2011). "The Effects of Situational and Individual Factors on Impulse Buying" World Applied Sciences Journal, 13(9); 2108-2117.

Babin, B.J., Darden, W.R., Griffen, M., 1994. Work and/or fun: measuring hedonic and utilitarian shopping value. Journal of Consumer Research 20 (4), 644-656.

Bitner, M.J., William, T., Faranda, A.R.H., Zeithaml, V.A., 1997. Customer contributions and roles in service delivery. International Journal of Services Industry Management 8 (3), 193-205.

Chatman, J.A., 1991. Matching people and organization: selection and socialization in public accounting firms. Administrative Science Quarterly 36 (2), 459-484.

Choi, sunmee, kim, sooyeon, 2013. Effects of a reward program on inducing desirable customer behaviors: The role of purchase , reward type and reward redemption timing. International Journal of Hospitality Management 32 (2013) 237-244

Cross, R.G., 1997. Revenue Management: Hard Core Tactics for Market Domination. Broadway Books, New York.

Dowling, G.R., Uncles, M., 1997. Do customer loyalty programs really work? Sloan Management Review 38 (4), 71-82.

Ganesan, S., 1994. Determinants of long-term orientation in buyer-seller relationship. Journal of Marketing 58 (1), 1-19.

Greenberg, J., 1987. Reactions to procedural injustice in payment distributions: do the means justify the ends? Journal of Applied Psychology 72 (2), 55-61.

Groth, M., 2005. Customers as good soldiers: examining citizenship behavior in Internet service deliveries. Journal of Management 31 (1), 7-27.

Heidarzadeh Hanzaee, Kambiz., (2014). "The impact of corporate social responsibility on customer satisfaction and corporate reputation in automotive industry Evidence from Iran" Vol. 5 No. 1, pp. 125-143.

Heidarzadeh Hanzaee, Kambiz; Khoshpanjeh, Mahsa \& Rahnama, Afshin., (2011). "Evaluation of the effects of product involvement facets on brand loyalty" African Journal of Business Management Vol. 5(16), pp. 6964-6971.

Homans, G., 1958. Social behavior as exchange. American Journal of Sociology 62,597-606.

Hsieh, A.T., Yen, C.H., Chin, K.C., 2004. Participative customers as partial employees and service provider workload. International Journal of Service Industry Management 15 (2), 187-199. 
Keh, H.T., Lee, Y.H., 2006. Do reward programs build loyalty for service? The moderating effect of satisfaction on type and timing of rewards. Journal of Retailing,82 (2), 127-136.

Kelley, S.W., Skinner, S.J., Donnelly Jr., J.H., 1992. Organizational socialization of service customers. Journal of Business Research 25 (3), 197-214.

Kimes, S.E., 1999. Implementing restaurant revenue management: a five-step approach. Cornell Hotel and Restaurant Administration Quarterly 40 (3), 16-21

Moorman, R.H., 1991. Relationship between organization justice and organizational citizenship behavior: do fairness perceptions influence employee citizenship? Journal of Applied Psychology 76 (6), 845-855.

Puffer, S.M., 1987. The motivational basis of organizational citizenship behavior. Research in Organizational Behavior 12, 43-72.

Rahnama, Afshin.,Alaei, Abbas., Shafaee, Javad., Ariana, Ali., 2012. "Evaluation of Relationship Marketing Dimension Effect on Degree of Customer's Loyalty of Insurance Industry in Iran" Journal of Basic and Applied Scientific Research, 2(2), 1842-1848.

Sadeghi, Tooraj; HeidarzadehHanzaee, Kambiz., (2010). "Customer satisfaction factors (CSFs) with online banking services in an Islamic country I.R. Iran" Journal of Islamic Marketing, Vol. 5 No. pp. 125-143.

Smith, B.C., Leimkuhler, J.F., Darrow, R.M., 1992. Yield management at American airlines. Interfaces 22 (1), 8-31.

Yi, Y., Gong, T., Yu, J.W., 2004. The effects of the exchange relationship between the service organizations and customers on customer citizenship behavior: the moderating role of customer experience. Korean Management Review 33 (6), 1809-1845. 